\title{
O ensino brasileiro e a relação com a democracia na enunciação do indígena
}

\author{
The Brazilian education and the relation with the democracy in the indigenous \\ enunciation
}

\author{
Marília Simplício Mairins ${ }^{1}$ \\ Secretaria de Estado de Educação de Mato Grosso do Sul \\ Rosimar Regina Rodrigues de Oliveira ${ }^{2}$ \\ Universidade Estadual de Mato Grosso do Sul
}

\begin{abstract}
- RESUMO: Este artigo tem como objetivo analisar nos enunciados constituídos pela resposta dada por um indígena, estudante de um curso de graduação da Universidade Estadual de Mato Grosso do Sul, a um questionário constituído com o objetivo de compreender os sentidos do ensino do não indígena para o indígena, na sociedade brasileira. Para tanto foi utilizado o dispositivo teórico e metodológico da Semântica do Acontecimento ou Semântica da enunciação, conforme proposta por Guimarães (2002, 2005, 20111, 2018 etc.), em que recorrermos a conceitos como: espaço de enunciação, acontecimento, cena enunciativa, designação e outros, necessários às análises realizadas. Assim, analisamos o funcionamento semântico-enunciativo da palavra "ensino brasileiro" na relação com "democracia" na enunciação do indígena.
\end{abstract}

- PALAVRAS-CHAVE: até Designação; Cena enunciativa; Ensino brasileiro; Indígena..

- ABSTRACT: This article has like objective to analyze in the enunciations constituted by indigenous ' answer, who is student of a graduation's course of the State University of Mato Grosso do Sul, these questions has the objective of understand the meaning of Education from non indigenous people to the indigenous people in Brazilian society. Therefore it was utilized the theoretical and methodological tools of semantics of the event or enunciation semantics, as proposed by Guimarães ( 2002, 2005, 2011, 2018 etc.), which resort to concepts like enunciation space, event, enunciative scene, designation and others necessary for the analyzes done. Therefore, analyse the semantic-enunciative operation of the word " Brazilian education" in the relation with "democracy" in the indigenous' enunciation.

- KEYWORDS: Designation, enunciative scene; Brazilian education; indigenous.

\section{Introdução}

Neste artigo propomos analisar o sentido de "ensino brasileiro" na relação com democracia, em funcionamento nos enunciados extraídos do questionário ${ }^{3}$ aplicado a indígenas ${ }^{4}$, que são alunos de graduação na Universidade Estadual de Mato Grosso do

\footnotetext{
${ }^{1}$ Mestra em Letras pela UEMS. Professora da rede estadual de educação, Secretaria de Estado de Educação de Mato Grosso do Sul. E-mail: lylape@bol.com.br

${ }^{2}$ Doutora em Linguística pela UNICAMP. Professora da Universidade Estadual de Mato Grosso do Sul; Professora Colaboradora no Programa de Pós-Graduação em linguística da Universidade do Estado de Mato Grosso. E-mail: rosiregio@gmail.com

${ }^{3}$ Esse questionário foi elaborado com o intuito de entrevistar o indígena em relação ao ensino do "não indígena", constituindo o corpus para análise no desenvolvimento da dissertação de Mestrado de Mairins (2018).

${ }^{4}$ De acordo com dados do Instituto Brasileiro Geográfico (IBGE), a população indígena do Estado do Mato Grosso do Sul é considerada a segunda maior do Brasil, composta pelas etnias: Terena, GuraniNhandeva, Guarani-Kaiwá, Guató, Kadwéu, Ofaié e Kinikinawa, perdendo apenas para o estado do
} 
Sul (UEMS), em Campo Grande/MS. Nessa medida, observamos como o ensino público, oferecido na sociedade brasileira sul-mato-grossense, pelo "não indígena", produz sentidos para o indígena, considerando as relações políticas, sociais, econômicas e culturais que constituem esses povos. Pensar o ensino do "não indígena" pelo olhar do indígena é desconstruir a direção costumeira do funcionamento social, que sempre atribuiu ao "não indígena" o direito de avaliar (atribuir valor), rotular e até desqualificar o funcionamento social e cultural dos povos indígenas.

A nossa unidade de análise é o enunciado, pensado de modo específico, possibilitando perceber os diferentes sentidos produzidos na linguagem em relação à sua exterioridade, enquanto historicidade, ou seja, na enunciação. Conforme Guimarães a enunciação é a representação da significação histórica "não no sentido temporal, historiográfico, mas no sentido de que a significação é determinada pelas condições sociais de sua existência. Sua materialidade é esta historicidade" (GUIMARÃES, 2005 p. 66). Assim, é preciso tomar como lugar de observação do sentido o enunciado que deve ser considerado na enunciação, enquanto acontecimento do funcionamento da língua, em um espaço de enunciação, produzindo sentido.

O acontecimento, conforme Guimarães (2011, p. 15), "faz diferença na sua própria ordem", pois ele constitui uma temporalidade específica: funciona por estar no presente da formulação do locutor. Além disso, projeta em si mesmo um futuro de sentidos e, por outro lado, tem um passado, enquanto memorável de enunciações; é esta temporalidade que o faz significar. Nesta medida, o acontecimento é um espaço de temporalização, sendo o passado uma rememoração de enunciações recortadas pelo acontecimento.

Observamos como os enunciados significam no acontecimento e se caracterizam integrando o texto, considerando que o "texto é uma unidade de sentido que integra enunciados no acontecimento de enunciação" (GUIMARÃES 2011, p.19). Sendo fundamental observar o funcionamento dos enunciados e os lugares de enunciação, que constituem os sujeitos ao enunciarem em relação à significação de "ensino brasileiro", para o indígena, na relação com "democracia".

Os enunciados contribuíram para a compreensão da construção de sentidos do "ensino brasileiro" para o indígena. Considerando que, ao longo de muitos anos, o ensino formal, realizado na e pela sociedade não indígena, não se estendia aos indígenas, tendo sido necessário criar leis para contemplá-los. Assim, somente a partir da Constituição de 1988 os indígenas passaram a ter direito ao ensino formal, ao acesso à escola na sociedade brasileira não indígena.

Desse modo, após analisarmos o sentido do ensino ${ }^{5}$ brasileiro para o indígena, e observarmos que ele é considerado como uma forma de adquirir conhecimento e qualificado como razoável, pois aparece em relações em que vai de bom a péssimo, sendo que precisa ser reinventado. Neste artigo, observamos como o indígena se posiciona em relação ao que vem a ser o "ensino brasileiro", o ensino do não-indígena, ofertado ao indígena, o que produz sentidos na relação do indígena com a sociedade não-indígena. Ou seja, como se dá a construção de sentidos no que se refere a si mesmo em relação ao outro (o não-indígena) e à sua condição na sociedade não-indígena.

\section{O Procedimento Descritivo e Analítico}

Amazonas. Mesmo sendo a segunda maior população indígena do Brasil, são poucos os que frequentam as universidades, fato esse que comprovamos nos cursos de graduação da UEMS.

${ }^{5}$ Conforme pode ser consultado na dissertação de Mairins, 2018. 
O objeto de pesquisa na área da Semântica é a língua em funcionamento produzindo "sentido, ou significação" (GUIMARÃES, 2005, p. 11), ou seja, trata-se de compreender que o sentido de um enunciado não está evidente numa expressão. Nessa perspectiva, analisar enunciativamente a designação de "ensino brasileiro" na relação com "democracia", tomada no acontecimento de linguagem é possível a partir dos procedimentos de reescrituração e articulação, constituindo o Domínio Semântico de Determinação, em que as palavras são colocadas na relação direta com as outras palavras que as determinam. Assim, para compreender o significado de uma palavra ou expressão é preciso analisar como a linguagem "'se reporta a', 'se relaciona a', 'diz de' alguma coisa" (GUIMARÃES, 2007, p.77), representando, por exemplo, o sentido de palavras como "ensino" na relação com "democracia", na enunciação do indígena.

No procedimento de articulação as relações semânticas se estabelecem através de elementos linguísticos, agenciados enunciativamente, que possibilitam a produção do sentido por combinação, se organizando estruturalmente na enunciação pelo "funcionamento de certas formas [que] afetam outras que elas não redizem" (GUIMARÃES, 2004a, p. 8), podendo ser por: dependência, incidência ou coordenação.

Quanto ao procedimento de reescrituração, se constitui numa textualidade linguística que "consiste em se redizer o que já foi dito" (GUIMARÃES, 2011, p. 46), produzindo outros sentidos, diferentes entre si. Esse procedimento possibilita observar as ligações entre diferentes pontos em um mesmo texto como também liga "pontos de um texto com pontos de outro texto", produzindo sentidos no acontecimento, na "operação enunciativa". São diversos os modos de reescrituração: repetição, substituição ou elipse, expansão, condensação (GUIMARÃES, 2018, p. 93).

A partir desses dois procedimentos, em que as relações entre as palavras são descritas no funcionamento da língua, é possível estabelecer o Domínio Semântico de Determinação $(D S D)$, em que são analisadas as relações enunciativas, constituindo a designação (GUIMARÃES, 2002). A relação de determinação demonstra o movimento de sentido de uma palavra ou expressão, que é representada por alguns símbolos específicos do DSD, que são: $\dashv$ ou $\vdash$ ou $\perp$ ou $T$, que lê "determina". Por exemplo: ensino $\dashv$ indígena (ensino determina indígena); o traço na posição horizontal dividindo o DSD —, significa a existência de antonímia e, na posição vertical, dividindo dois DSDs, significa que há sinonímia entre os DSDs.

A designação, enquanto estudo do funcionamento dos nomes, é analisada no acontecimento da enunciação. Sendo a enunciação constituída nas e pelas relações entre as línguas e seus falantes, no espaço de enunciação (GUIMARÃES, 2018), espaço político em que se dá o agenciamento dos falantes pelas línguas. Assim, enunciar é uma prática política. Sendo que o político é o conflito que se estabelece a partir da relação contraditória na divisão do real, divisão que é normativa e que ocorre de forma desigual. Essa divisão, ao estabelecer uma desigualdade nas relações sociais, gera incluídos e excluídos (se faz como conflito). Os excluídos são aqueles a quem a palavra é negada. Mas, é preciso considerar que o homem sempre assume a palavra, mesmo que ela lhe seja negada, desse modo os excluídos afirmam o seu pertencimento no conflito. É essa contradição que instala o conflito no centro do dizer e produz para o político uma divisão "pela desmontagem da contradição que o constitui".

Conforme Guimarães (2002), a enunciação se dá nos espaços de enunciação que são espaços políticos; espaços de distribuição de línguas, de modos de dizer e do que dizer, para seus falantes. Sendo esses lugares de dizer constitutivos da cena enunciativa, que é "um espaço particularizado por uma deontologia específica de distribuição dos lugares de enunciação no acontecimento" (GUIMARÃ̃ES, 2002, p. 23). 
De acordo com o autor, os lugares de enunciação são configurações do agenciamento enunciativo para "aquele que fala" e "aquele para quem se fala", mas são lugares constituídos pela linguagem não pelas pessoas. Assim, é a partir do agenciamento enunciativo que ocorre a assunção da palavra e a constituição desses lugares de dizer.

Ao ser agenciado no e pelo funcionamento da língua o falante é constituído em Locutor (aquele que diz) e diz para alguém, sustentando uma enunciação, sendo agenciado como "aquele que fala para alguém (seu Locutário) enquanto tomado no mesmo espaço de enunciação, constituindo uma relação específica no acontecimento" (GUIMARÃES, 2018, p. 55). Nesse acontecimento enunciativo há também um alocutor (alocutor- $x^{6}$ ) que diz a seu alocutário (alocutário- $x$ ), constituídos enquanto lugar social. Assim, temos, por exemplo: o alocutor-indígena que diz para o alocutário-representante universitário. Esse funcionamento da língua, pelo agenciamento enunciativo, é constituído na e pela "cena enunciativa", configurando as relações de alocução. Nessas relações, o responsável pelo dizer e pela unidade do texto é o Locutor, enquanto o alocutor, que é o lugar social de dizer, estando em confronto com o Locutor, significa a não unidade e a não intencionalidade de quem diz (GUIMARÃES, 2018). Esta disparidade, conforme o autor (idem), é política e é própria da divisão do falante no acontecimento da enunciação, divisão que constitui a politopia da cena enunciativa.

Além desses lugares de enunciação, há o lugar de dizer, que, de acordo com Guimarães $(2002$; 2018) constitui o enunciador e pode ser individual, coletivo, universal, genérico, por exemplo, entre outros. Esse lugar de dizer também é constitutivo da cena enunciativa. Essas relações de constituição da cena enunciativa são representadas por Guimarães (2018, p. 61), da seguinte forma:

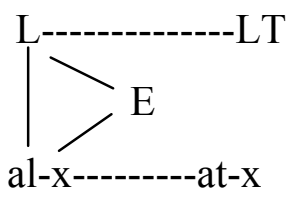

Esse funcionamento enunciativo constitui uma temporalidade que é própria do acontecimento (GUIMARÃES, 2002, p.12), apresentando um passado, enquanto "rememoração de enunciações", que atribui sentidos ao acontecimento analisado; um presente, que é próprio do funcionamento da enunciação; e um futuro, enquanto uma projeção de sentidos, que poderão compor outras enunciações (GUIMARÃES, 2018). Sendo que a temporalidade funciona na relação tomada das práticas sociais, a partir do agenciamento enunciativo, em que, como dissemos acima, o Locutor ao dizer, o faz de um lugar social, enquanto lugar autorizado, estando dividido na cena enunciativa (GUIMARÃES, 2002) e produzindo determinados sentidos e não outros.

É nessas relações, que consideramos a cena enunciativa, constituída pelo lugar social de enunciação do indígena, no espaço de enunciação "brasileiro", "sul-matogrossense". Nesse espaço em que é negado a ele o direito ao dizer, portanto, a ocupar um lugar social, mas que ele diz, produzindo sentidos, fazendo-se significar.

\section{A Educação para o Indígena no Brasil}

No Brasil, a educação escolar foi empregada como um recurso de iniciativas civilizatórias e integração à sociedade nacional, sendo implementada pela Coroa

\footnotetext{
${ }^{6} \mathrm{O}$ " $\mathrm{x}$ " representa o lugar social de onde o alocutor e/ou o alocutário estão enunciando.
} 
Portuguesa, pelo império e pela república. Do século XVI até a última década do século XX a oferta de educação escolar às comunidades indígenas se deu por meio da catequização, que era ofertada pelos missionários jesuítas e, posteriormente, pelos funcionários das agências indigenistas do Estado.

Embora, o ensino fosse ministrado na língua nativa, não descartava o interesse de imposição da nacionalidade europeia de catequizar e civilizar o indígena. Durante a administração imperialista o indígena recebeu interferência da educação também através da imposição da Igreja Católica com os mesmos interesses, considerado uma forma de conversão a uma cultura branca, cristã, europeia e dominante.

O indígena recebia a educação colonial com a intenção de "por feição dominante, para todos os efeitos da colonização" (JÚNIOR, 1987, p.349), cuja finalidade era não somente civilizá-los, mas também para modelá-los às condições de produção, por serem considerados, dentre outros fatores, o "poderoso inimigo destes habitantes e a mais poderosa causa entre muitas outras de seu atraso é a preguiça deles" (Idibem).

De imediato os portugueses não tinham intenção de habitar nas terras brasileiras, porque o interesse era especificamente econômico. Dando ênfase a expressão de desprezo ao território considerado "primitivo" e "vazio que é América" (Idibem, 23). Diante do crescimento comercial a população indígena passa a ser alvo no que confere as práticas sociais, visando sua integração na sociedade e automaticamente assimilando-a a outra cultura por meio da educação, que favorece o crescimento econômico do comércio e da indústria.

A educação dada ao indígena contribui no "abrandamento dos costumes, educação dos espíritos, desenvolvimento da polidez, cultura das artes e das ciências, crescimento do comércio e da indústria, aquisição das comodidades materiais e do luxo" (STAROBINSKI, 2008, p.14), favorecendo ao processo de transformação na vida do povo indígena. Dessa maneira a política educacional destinada à população indígena, visava sua integração na relação social entre estrangeiros e povo nativo, sendo a educação uma forma de "discipliná-los e reduzi-los a condição de dominados" (TOMMASINO, 2003).

Durante o século XX, a educação formal passou a ser trabalhada por professores leigos, assumindo a função de reproduzir as políticas integracionistas, sem levar em consideração a especificidade da cultura e da história indígena, além de ter contribuído e incentivado a prática monolíngue da língua portuguesa (TOMMASINO, 2003). Com a criação de leis para garantir a inclusão do cidadão, nos diversos âmbitos sociais, abriu-se um leque para discussões a respeito do sistema de ensino brasileiro como forma de "redemocratização"7 . Assim, a inserção da cidadania contribui para a mudança da sociedade.

A Promulgação da República, em 1889, com forte influência positivista, difundiu a ideia que os povos indígenas pertenciam a um estágio primitivo, e que precisavam chegar à civilização. De acordo com registros históricos, durante a organização da sociedade brasileira, são apresentadas fortes características negativas atribuídas ao povo indígena, como deterioração enquanto sujeito pensante, incapaz e não contribuinte para o desenvolvimento econômico do país.

Criaram-se, então, o Serviço de Proteção ao Índio e Localização de Trabalhadores Nacionais - SPILT. O Serviço de Proteção ao Índio - SPI, é substituído em 1967 pela Fundação Nacional do Índio - FUNAI, com a função social de proteção e fiscalização na garantia dos direitos do povo indígena. Assim, a FUNAI foi criada tendo

\footnotetext{
${ }^{7}$ Escrita de acordo com o Referencial Curricular do Ensino Médio de Mato Grosso do Sul (2012, p.22).
} 
o objetivo de preparar a autonomia e uma retomada ao contexto social, político e econômico do indígena; e comprometida na constituição identitária afirmativa para a promoção da tradição desse povo.

Somente a Constituição Federal de 1988 irá assegurar que a educação escolar indígena respeite as especificidades, ao reconhecer a pluralidade cultural e linguística dos povos indígenas. Assim, a partir desse contexto histórico, é possível fazer uma ponte entre os conteúdos a serem desenvolvidos, de acordo com os Parâmetros Curriculares Nacionais de Educação e da aprendizagem, garantindo que, as aulas sejam ministradas na língua portuguesa, porém permitindo o uso da língua materna.

Na textualidade da Constituição Brasileira de 1988 designa a educação como fator determinante na vida do sujeito na sociedade, afirmando a necessidade do "[...] seu preparo para o exercício da cidadania e sua qualificação para o trabalho" (art. 205). Em consonância com a Constituição, a LDB, de 1996, traz um conceito de cidadania como finalidade da educação básica; e a partir dessa proposta a palavra educação passa a constituir outro sentido ao considerar a formação para a cidadania como essencial, enquanto possibilidade de acesso ao conjunto de direitos sociais e humanos inerentes a toda pessoa.

A promulgação Constitucional pode ser interpretada como um marco histórico e importante para os povos indígenas, no que se refere aos direitos constitucionais em que estão expressas a liberdade e o reconhecimento da diversidade cultural. Por outro lado, pode ser interpretada como uma forma de exclusão pela sociedade ao considerar a diversidade social e fazer distinções.

Em 04 de fevereiro de 1991 é aprovado o Decreto n. 26/91, em que a Educação Escolar Indígena passa a ser responsabilidade do Ministério da Educação (MEC), incumbido de organizar e coordenar as ações desenvolvidas pelas Secretarias Estaduais e Municipais para atender a população indígena.

A Lei de Diretrizes e Bases (LDB) - Lei no 9.394 de 20 de dezembro de 1996, apresenta uma proposta educacional diferenciada, por ser intercultural e bilíngue (ou multilíngue), aos povos indígenas. Para que estes sujeitos tenham condições de resgatar, fortalecer e valorizar suas práticas socioculturais, por meio de suas memórias e da língua materna. Também dispõe de orientações para o desenvolvimento de programas que integrem e envolvam a comunidade indígena.

\footnotetext{
Art. $79^{\circ}$. Os programas integrados de ensino e pesquisa, para a oferta de uma educação escolar bilíngüe e intercultural aos povos indígenas, com os seguintes objetivos:

I - proporcionar aos índios, suas comunidades e povos, a recuperação de suas memórias históricas; a reafirmação de suas identidades étnicas; a valorização de suas línguas e ciências;

II - garantir aos índios, suas comunidades e povos, o acesso às informações, conhecimentos técnicos e científicos da sociedade nacional e demais sociedades indígenas e não-índias. (BRASIL, 2010)
}

Desde o começo da história de constituição da sociedade brasileira as políticas voltadas ao indígena sempre tiveram como objetivo "civilizar" o índio e torna-lo "trabalhador nacional", de acordo com Tommazino (2003, p. 73). Conforme a autora, "isso só mudou com a promulgação da Constituição de 1988, que reconheceu o direito aos povos indígenas de viverem segundo suas especificidades socioculturais".

Analisando os direitos previstos e determinados pela lei, podemos perceber como os enunciados se deslocam na construção de sentidos, no que tange ao modo de considerar o indígena enquanto não pertencente, não incluído na sociedade brasileira e, 
por isso silenciado, não reconhecido em seus direitos mínimos como humano ${ }^{8}$. Vindo a ter o direito a viver a sua cultura, somente a partir de 1988, com a promulgação da Constituição Federal Brasileira. Porém, mesmo tendo seus direitos sustentados em Lei, não há garantias ao cumprimento dessa Lei.

Considerando todo esse contexto é possível observar como os sentidos foram se construindo em relação ao indígena, desde a "colonização" do Brasil por Portugal. Esses sentidos reverberam e afetam o indígena até hoje, inclusive, muitas vezes, não o reconhecendo como cidadão brasileiro nem reconhecendo seu direito à educação igualitária e democrática.

\section{O Funcionamento Semântico-Enunciativo}

Nesta análise propomos uma reflexão sobre o sentido de "ensino brasileiro" na relação com a palavra "democracia", em funcionamento nos enunciados coletados a partir de um questionário aplicado a alunos indígenas ${ }^{9}$, que estão realizando algum curso de nível superior na Universidade Estadual de Mato Grosso do Sul, em Campo Grande. Porém, antes de realizarmos as análises, observaremos como a palavra democracia é conceituada no Dicionário Michaelis, da Língua Portuguesa.

\subsection{A palavra democracia}

A palavra democracia, no dicionário brasileiro Michaelis, apresenta uma diversidade de definições, sendo quase todas relacionadas a sistema de governo ou à política; mas, há uma definição que aborda, de modo mais específico e direto, as relações entre cidadãos, é a seguinte: "Forma de governo que tem o compromisso de promover a igualdade entre os cidadãos". Ou seja, por essa definição, a democracia é um modelo em que o governo tem a função de garantir que os cidadãos sejam reconhecidos e tratados sem distinção.

Assim, é preciso olhar para a definição de cidadão. Consultando o mesmo dicionário, Michaelis, também encontramos uma diversidade de definições, como, por exemplo: "Habitante de uma cidade" e o "Indivíduo no gozo dos direitos civis e políticos de um Estado". Considerando a relação com a palavra democracia, a definição que interessa a esta discussão é a que atribui direitos ao "cidadão" e o relaciona ao Estado, portanto: "Indivíduo no gozo dos direitos civis e políticos de um Estado". Assim, todo o indivíduo que exerça seus direitos civis e políticos pode ser considerado cidadão.

Nessa direção, interessa-nos analisar como o indígena significa o ensino do não-indígena que é ofertado ao indígena; e, a partir da sua compreensão do ensino brasileiro, como o indígena significa a sua relação com a democracia no Estado brasileiro.

\subsection{A constituição da cena enunciativa para ensino democrático}

A partir dos enunciados abaixo, que constituem um recorte das respostas dadas por alunos indígenas, que cursam graduação na UEMS, analisaremos como o ensino brasileiro estabelece uma relação com democracia, na construção dos sentidos, na enunciação: a partir das relações estabelecidas entre as palavras, que direcionam a uma determinação entre elas; e, a partir da divisão dos lugares de enunciação na constituição

\footnotetext{
${ }^{8}$ A esse respeito ver Oliveira, 2018.

${ }^{9}$ Para este artigo analisamos apenas 1 recorte constituído da resposta a uma pergunta do questionário.
} 
da cena enunciativa. Assim, foi feita a seguinte pergunta ${ }^{10}$, correspondente à resposta que compõe o recorte que será analisado na sequência: 11 .Você considera que o ensino brasileiro é democrático para atender ao indígena? Cuja resposta é:

[1]. "Em partes sim, quando há vagas direcionadas para esse público. Porém muitas instituições precisam ainda aderi”. (E. 2; Q. 11)

Esse recorte constitui-se para nós de três enunciados: "em partes sim"; "quando há vagas destinadas a esse público"; "porém muitas instituições precisam ainda aderi”, cuja abordagem poderá ser melhor compreendida adiante, no decorrer das análises. No enunciado "quando há vagas direcionadas a esse público" percebemos a divisão política entre os falantes no espaço de enunciação, que se constitui desigualmente (GUIMARÃES, 2002), uma vez que há "alguém" que ocupa um lugar autorizado a dizer a qual público as vagas das cotas serão destinadas ${ }^{11}$. Há, então, um alocutor que diz ao seu alocutário, "há cotas para você" ou "não há cotas para você". Alguém que diz qual público poderá ocupar o lugar de cotista: cotista indígena, cotista pardo, cotista negro. Esse lugar é constituído na e pela enunciação, a partir do agenciamento enunciativo que autoriza a uns e interdita a outros, conforme Guimarães $(2002,2018)$.

O conjunto de enunciados [1]. "Em partes sim, quando há vagas direcionadas para esse público. Porém muitas instituições precisam ainda aderi” (E. 2; Q. 11), produz sentidos, marcado pela enunciação de um Locutor que diz do lugar de estudante indígena, mas que enuncia do lugar social de alocutor-estudante não indígena. Esse alocutor-x ou al-estudante não indígena sustenta a posição de quem é capaz de avaliar a condição do ensino brasileiro enquanto democrático ou não para atender ao indígena. Porém, enuncia enquanto al-estudante não indígena, uma vez que, ao dizer das "vagas destinadas para esse público", refere-se ao indígena enquanto "esse público”, ou seja, não se inclui a ele.

O al-x ao enunciar fala a um tu, o at-x (alocutário-x), apontando as condições necessárias para que o ensino brasileiro seja democrático. Esse al-estudante não indígena enuncia ao at-universidades públicas, que "precisam ainda aderi" ao sistema instituído pela Lei cotas ${ }^{12}$ para indígenas.

Nesses lugares de enunciação, há o Locutor, o responsável pelo dizer e pela unidade do que está sendo dito, que diz enquanto estudante indígena, porém, ao enunciar, de um lugar social, o faz enquanto alocutor-estudante não indígena. Assim,

\footnotetext{
${ }^{10}$ Foram elaboradas e aplicadas 38 perguntas a 5 entrevistados, que poderiam responder ou não ao questionário. Muitas perguntas foram respondidas apenas com "sim" ou "não", não apresentando justificativas ou explicações. À pergunta 11, por exemplo, somente a resposta que analisamos apresentou uma explicação, as demais foram: (E.1) "em partes", (E. 3) "não", (E. 4) "sim” e (E. 5) "sim".

${ }^{11}$ Em relação às cotas, no que se refere às Universidades e Institutos Federais, a definição é dada pelo Congresso Nacional e pelo (a) Presidente da República. Assim, temos: o locutor-Congresso Nacional e locutor-Presidente da República. Quanto às Universidades Estaduais, o sistema de cotas pode ser definido por meio de leis estaduais ou por políticas internas às próprias universidades a partir de regulamentos internos, normalmente elaborados e aprovados por seus representantes: comissões de responsáveis por políticas de inclusão, pró-reitorias, reitorias.

${ }^{12}$ Sendo o sistema de cotas estabelecido a partir da Lei de Cotas, cujo objetivo é contemplar os diferentes grupos sociais, considerados socialmente excluídos, garantindo os seus direitos ao ensino. Os grupos contemplados pela Lei de Cotas são 3, sendo: 1: cursou o ensino médio em escola pública - mediante comprovação; 2: famílias com baixa renda - mediante comprovação; 3: pretos, pardos e indígenas autodeclarados e pessoas com deficiência.

Pela Lei de Cotas são atendidos somente aqueles que comprovam sua condição social ou física ou, no caso da diversidade étnica: pretos, pardos e indígenas, desde que se autodeclarem.
} 
está significado o confronto com o Locutor, a não unidade, que de acordo com Guimarães (2018), marca a não intencionalidade de quem diz.

Ao enunciar do lugar social de al-estudante não indígena, são produzidos sentidos constituídos a partir do memorável de interdição ao indígena, da exclusão, em que a ele é negada a palavra. Desse modo, no conflito, entre o Locutor (estudante indígena) e o alocutor-estudante não indígena, está sendo afirmado o seu pertencimento ao grupo de estudantes brasileiros, portanto, ao povo brasileiro, e, por isso, a ter direitos iguais ao "ensino brasileiro". Sendo que, é somente a partir desse reconhecimento, dessa inclusão que o ensino brasileiro poderá ser considerado democrático.

Tomando o mesmo recorte: [1]. "Em partes sim, quando há vagas direcionadas para esse público. Porém muitas instituições precisam ainda aderi”. (E. 2; Q. 11), podemos parafraseá-lo por:

[1.a] (Sabemos que) O ensino brasileiro é democrático em partes,

[1.b] (Eu afirmo que) $\mathrm{O}$ ensino brasileiro é democrático quando há vagas direcionadas para o público indígena.

[1.c] Porém, (Eu afirmo que) para que o ensino brasileiro seja democrático muitas instituições precisam ainda aderir ao sistema de cotas para indígenas.

Nesse funcionamento da enunciação, vamos observar os lugares de dizer, o que Guimarães $(2002 ; 2018)$ chama de enunciador. Entre as paráfrases acima, podemos dizer que em [1.a] há um enunciador coletivo que afirma junto com outras vozes que "sabemos que o ensino brasileiro é democrático "em partes"”. Desse modo, está significado pelo "nós sabemos" (representando o lugar de dizer de uma coletividade, que pode ser representado pelo grupo de estudantes), referindo-se ao grupo de que faz parte o alocutor-estudante não indígena. Esse grupo afirma a existência de um ensino democrático "em partes", ou seja, para atender a alguns.

Em contraposição a [1.a], em [1.b] há um enunciador individual que afirma que "eu sei que o ensino brasileiro é democrático quando há vagas direcionadas para 'esse público' (indígena)", esse enunciador apresenta condições em que o ensino pode ser democrático; e, em [1.c] há também o enunciador individual que está marcado pelo articulador "porém", que indica a oposição do enunciador individual ao enunciador coletivo. Esses lugares marcados pelo "quando" e pelo "porém" sustentam uma posição que é contrária à posição do enunciador individual, e apontam que o ensino brasileiro não é democrático. Assim, é indicada uma solução para que o ensino brasileiro se torne democrático: "para que $\mathrm{o}$ ensino brasileiro seja democrático muitas instituições/universidades precisam ainda aderir ao sistema de cotas para indígenas".

Assim, temos nesse conjunto de enunciados uma posição em que há uma coletividade que diz o ensino brasileiro é "em partes" democrático, mas que, diante dos argumentos apresentados pelo enunciador individual, o ensino brasileiro não é democrático.

\subsection{A constituição da Designação}

No conjunto de enunciados constituídos a partir da pergunta ao estudante indígena: (Q.11) "Você considera que o ensino brasileiro é democrático para atender ao indígena?" em que se tem a resposta: [1]. "Em partes sim, quando há vagas direcionadas para esse público. Porém muitas instituições precisam ainda aderi” (E. 2; Q. 11), analisaremos também o funcionamento da designação, ou seja, da constituição dos sentidos a partir das relações que as palavras estabelecem entre si. Para tanto, esse conjunto de enunciados pode ser parafraseado da seguinte forma: 
[1.1] O ensino brasileiro é democrático em partes.

[1.2] O ensino brasileiro é democrático quando há vagas direcionadas ao público indígena.

[1.3] Porém, para que o ensino brasileiro seja democrático, muitas instituições precisam ainda aderir ao sistema de cotas.

Nesse conjunto de enunciados pode-se perceber que ao dizer "em partes sim" é minimizado o sentido atribuído ao ensino brasileiro enquanto democrático ou não. $\mathrm{Ou}$ seja, não é negada nem afirmada a existência de um ensino realmente democrático; mas o "quando" introduz as circunstâncias imprevistas em que o ensino funciona ou pode funcionar democraticamente.

Nessas relações, o "ensino brasileiro" é reescriturado por especificação, em que "é pouco democrático" ou "é democrático em partes", o que especifica o ensino. Sendo que o que define ser democrático ou não, para o ensino brasileiro, é a existência ou não de vagas para o indígena, pelo sistema de cotas. Assim, é possível apresentar o DSD 1:

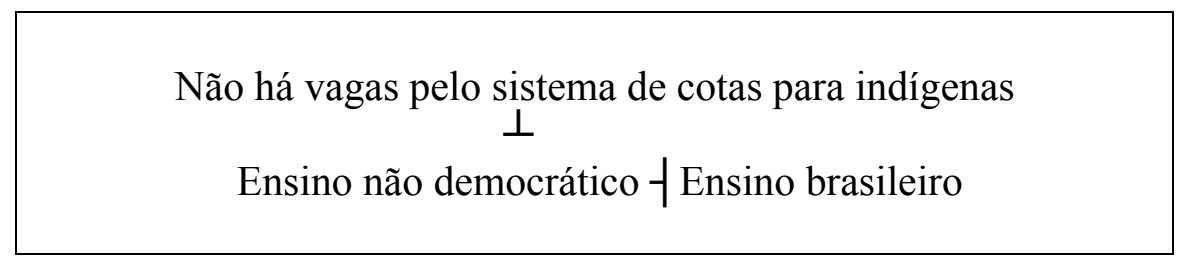

Nesse conjunto de enunciados, que constitui a resposta à pergunta (Q. 11), acima, o articulador "porém" articula os enunciados anteriores por coordenação, marcando a oposição entre os enunciados anteriores e este, em que a relação argumentativa se constitui ao marcar a posição do alocutário-estudante (não indígena) que apresenta uma solução para que o ensino brasileiro seja democrático: a adesão das universidades ao sistema de cotas para indígenas.

Desse modo, o "porém" atribui o sentido de que não há vagas, uma vez que muitas instituições/universidades não aderiram ao sistema de cotas, portanto o ensino brasileiro não é democrático, devido à não adesão de muitas instituições a esse sistema. Para que o ensino brasileiro seja democrático é preciso haver vagas suficientes, pelo sistema de cotas, nas instituições que atendem aos indígenas. Desse modo, temos o DSD 2:

$$
\begin{gathered}
\text { Instituições/universidades } \dashv \text { não há vagas pelo sistema de cotas para indígenas } \\
\perp \\
\text { Ensino não democrático } \dashv \text { Ensino brasileiro }
\end{gathered}
$$

Considerando que a democracia está atrelada à condição de igualdade para todos, então, se não contempla a todos, não há democracia. Desse modo, o ensino que não contempla a todos não é democrático. Por essas relações apresentadas nos DSDs $1 \mathrm{e}$ 2, acima, em que é o "ensino não democrático" que está determinando o "ensino brasileiro", é possível constituir o DSD 3: 
Existência de vagas pelo sistema de cotas para indígenas $\dashv$ Ensino democrático

Instituições/universidades $\dashv$ quase não há vagas pelo sistema de cotas para indígenas $\perp$

Ensino brasileiro

\section{Algumas Considerações}

As análises realizadas nos permitiram observar, no funcionamento da cena enunciativa, que há um Locutor (L) que, ao ser agenciado, constitui o lugar do Locutário (LT), sendo instituído o lugar social de locutor (al-x), Alocutor-estudante não indígena, que projeta o lugar do seu alocutário-universidades brasileiras (at-x). Esse alestudante não indígena afirma a existência de um ensino brasileiro que não atende ao indígena, não sendo democrático e apresenta as condições necessárias para que o ensino brasileiro se torne democrático. Ou seja, é preciso dizer do lugar de "não-indígena" para apresentar as condições nas quais é possível sustentar uma posição.

A cena enunciativa apresenta ainda um enunciador que, ao enunciar do lugar de dizer de enunciador coletivo diz, com outras vozes, da existência de um ensino democrático para atender a alguns; e, do lugar de dizer de enunciador individual afirma a existência de um ensino não democrático para atender ao indígena. Sendo a democracia o direito à inclusão, à igualdade, se o ensino brasileiro não é igualitário no atendimento ao indígena, então não é democrático. Nessa medida, o indígena não tem direito à igualdade, ao ensino democrático.

Pelas relações apresentadas nos DSDs acima, o que determina o ensino democrático é a existência de um sistema de cotas que atenda ao indígena, sendo que são as instituições/universidades que aderem ao sistema de cotas liberando as vagas. Desse modo, são as instituições/universidades que determinam a existência de um ensino brasileiro enquanto democrático ou não. Considerando que não há vagas para atender aos indígenas, pelo sistema de cotas, então o ensino brasileiro não é democrático no atendimento ao indígena, portanto, não é democrático.

\section{REFERÊNCIAS}

BRASIL, Ministério da Educação. Secretaria de educação Básica. Diretrizes e Bases da Educação Nacional. 5. ed. Brasília, 1996.

. [Lei Darcy Ribeiro (1996)], LDB: Lei de Diretrizes e Bases da Educação Nacional: lei n. 9394, de 20 de dezembro de 1996, que estabelece as diretrizes e bases da educação nacional. 5. ed. Brasília: Câmara dos Deputados, edições Câmara, 2010.

. Ministério da Educação, Secretaria de Educação Básica. Diretrizes

Curriculares Nacionais para a Educação Escolar Indígena na Educação Básica. CNE/CBE, Brasília: MEC/SEB, 2012.

Congresso Nacional. Constituição da República Federativa do Brasil, de 1988. Brasília: Assembleia Nacional Constituinte/Congresso Nacional, 1988.

JÚNIOR. Caio Prado. Formação do Brasil Contemporâneo. São Paulo: São Paulo, 1987. 
GUIMARÃES, Eduardo. Semântica do Acontecimento: um estudo enunciativo da designação. Campinas, SP: Pontes, 2002.

Bairro: a especificidade de um nome abstrato. (in) MORELLO, Rosângela (org.) Giros na Cidades: saber urbano e linguagem. Campinas, SP: LABEURB/NUDECRI - UNICAMP, 2004a.

Os Limites do sentido: um estudo histórico enunciativo da linguagem. 3. ed. Campinas, SP: Pontes, 2005.

. Semântica e Pragmática. In: GUIMARÃES, Eduardo; ZOPPI-FONTANA, Mónica. A palavra e a frase. Campinas, SP: Pontes, 2006.

Domínio Semântico de Determinação (in.) GUIMARÃES, Eduardo e MOLLICA, Maria Cecília (orgs.) A palavra forma e sentido. Campinas, SP: Pontes Editores, RG Editores, 2007.

RG, 2011.

Análise de texto: procedimentos, análises, ensino. Campinas, SP: Editora

Semântica, enunciação e sentido. Campinas, SP: Pontes, 2018.

MATO GROSSO DO SUL. Referencial Curricular da Educação Básica da Rede Estadual de Ensino. Secretaria de Estado de Educação. Superintendência de Políticas de Educação. Campo Grande: SED, 2012.

MAIRINS, Marília Simplício. O sentido do "ensino" do não-indígena para o indígena no acontecimento enunciativo. Campo Grande, UEMS, 2018. 85 p. Dissertação (Mestrado) - Programa de Pós-Graduação em Letras da Universidade Estadual de Mato Grosso do Sul, MS, 2018.

Michaelis Dicionário Brasileiro da Língua Portuguesa. Democracia. Disponível em: https://michaelis.uol.com.br/moderno-portugues/busca/portugues-

brasileiro/democrACIA/. Acesso em 10 de fevereiro de 2020.

OLIVEIRA, Rosimar Regina Rodrigues. "A marcha para o Oeste" no Brasil: entre a civilização e o sertão. São Paulo, UNICAMP, 2013. 208 f. Tese (Doutorado) Programa de Doutorado em Linguística no Instituto de Estudos da Linguagem da Universidade Estadual de Campinas, SP, 2013.

Os selvagens indígenas e a necessidade de civilização na enunciação da marcha para Oeste. In. Linguagem e significação: sujeitos indígenas. OLIVEIRA, Rosimar Regina Rodrigues de; OLIVEIRA, Sheila Elias de; RODRIGUES, Marlon Leal; KARIM, Taisir Mahmudo (orgs). Campinas, SP: Pontes Editores, 2018.

STAROBINSKI, Jean. As máscaras da civilização. Trad. Maria Lúcia Machado. São Paulo: Companhia das Letras, 2001.

TOMMASINO, kimiye. A educação escolar indígena no Paraná. Revista Mediações, Londrina, v. 8, n. 1, p. 71-98, jan./jun. 2003. Disponível em: http://www.uel.br/revistas/uel/index.php/mediacoes/article/view/9089. Acesso em: 10 de fevereiro de 2020.

Recebido em: novembro de 2019.

Aprovado em: dezembro de 2019.

\section{Como citar este trabalho:}

MAIRINS, M. S.; OLIVEIRA, R. R. R. de. O ensino brasileiro e a relação com a democracia na enunciação do indígena. Traços de Linguagem. V.3, n.2, p. 73-84, 2019. 